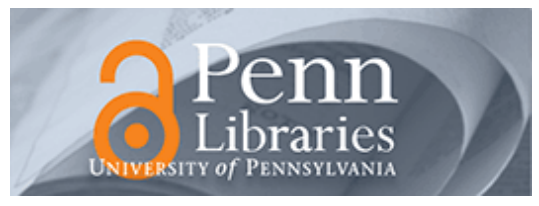

University of Pennsylvania

ScholarlyCommons

Management Papers

Wharton Faculty Research

8-2008

\title{
Social Capital in the Workplace: Evidence on its Formation and Consequences
}

Oriana Bandiera

Iwan Barankay

University of Pennsylvania

Imran Rasul

Follow this and additional works at: https://repository.upenn.edu/mgmt_papers

Part of the Business Administration, Management, and Operations Commons

\section{Recommended Citation}

Bandiera, O., Barankay, I., \& Rasul, I. (2008). Social Capital in the Workplace: Evidence on its Formation and Consequences. Labour Economics, 15 (4), 724-748. http://dx.doi.org/10.1016/j.labeco.2007.07.006

This paper is posted at ScholarlyCommons. https://repository.upenn.edu/mgmt_papers/153

For more information, please contact repository@pobox.upenn.edu. 


\title{
Social Capital in the Workplace: Evidence on its Formation and Consequences
}

\begin{abstract}
The existence of social ties between co-workers affect many aspects of firm and worker behavior, such as how workers respond to a given set of incentives, the optimal compensation structures for workers at different tiers of the firm hierarchy, and the optimal organizational design for the firm. This paper presents evidence on the social capital in one particular firm, as embodied in the friendship ties among its workers. We describe the structure of the friendship network as a whole and present evidence on the determinants of social ties. Finally, we review evidence from a field experiment we conducted in the firm to highlight one particular mechanism through which social capital significantly affects worker performance.
\end{abstract}

\section{Keywords}

productivity, social capital

Disciplines

Business Administration, Management, and Operations 


\title{
Social Capital in the Workplace: Evidence on its Formation and Consequences*
}

\author{
Oriana Bandiera $^{\dagger} \quad$ Iwan Barankay ${ }^{\ddagger} \quad$ Imran Rasul $^{\S}$ \\ June 2007
}

\begin{abstract}
The existence of social ties between co-workers affect many aspects of firm and worker behavior, such as how workers respond to a given set of incentives, the optimal compensation structures for workers at different tiers of the firm hierarchy, and the optimal organizational design for the firm. This paper presents evidence on the social capital in one particular firm, as embodied in the friendship ties among its workers. We describe the structure of the friendship network as a whole and present evidence on the determinants of social ties. Finally, we review evidence from a field experiment we conducted in the firm to highlight one particular mechanism through which social capital significantly affects worker performance.
\end{abstract}

Keywords: productivity, social capital.

JEL Classification: D21, J33, M52.

${ }^{*}$ We thank the editor, two anonymous referees, Alec Levenson, and participants at the Conference on the Analysis of Firms and Employees in Nuremberg 2006 for useful comments. This paper has been screened to ensure no confidential information is revealed. Financial support from the ESRC is gratefully acknowledged. All errors remain our own.

${ }^{\dagger}$ Department of Economics, London School of Economics and Political Science, Houghton Street, London WC2A 2AE, United Kingdom; Tel: +44-207-955-7519; Fax: +44-207-955-6951; E-mail: o.bandiera@lse.ac.uk.

$\ddagger$ Department of Economics, University of Warwick, Coventry CV4 7AL, United Kingdom; Tel: +44-24-76523935; Fax: +44-24-7652-3032; E-mail: iwan.barankay@warwick.ac.uk.

$\S$ Department of Economics, University College London, Drayton House, 30 Gordon Street, London WC1E 6BT, United Kingdom. Tel: +44-207-679-5853; Fax: +44-207-916-2775; E-mail: i.rasul@ucl.ac.uk. 


\section{Introduction}

This paper studies the formation of social capital in a firm - as embodied in the network of friendship ties between its workers. The idea that human relations affect performance in the workplace has been long recognized [Marshall 1890, Mayo 1933, Barnard 1938, Roethlisberger and Dickson 1939, Roy 1952, Bewley 1999], and there is now a burgeoning theoretical literature incorporating such social concerns into the analysis of behavior within firms [Encinosa et al 1987, Kandel and Lazear 1992, Rotemberg 1994].

Moreover, the increasing availability of personnel data has allowed progress to be made in identifying the qualitative importance that social ties between co-workers have on worker behavior [Ichino and Maggi 2000, Bandiera et al 2005, Mas and Moretti 2006]. ${ }^{1}$

The existence of social ties between workers can be beneficial to the firm's overall performance if socially tied workers are, for example, more likely to cooperate and share information with each other [Lazear 1989, Ichniowski and Shaw 2005], more likely to trust each other and so not engage in opportunistic behavior [Nagin et al 2002, Fehr and List 2004], more likely to internalize any positive externalities their behavior has on their friends within the firm because of social pressures or mutual monitoring [Mas and Moretti 2006], or because workers are compensated according to team pay [Jones and Kato 1995, Knez and Simester 2001, Hamilton et al 2003, Hayes et al 2006].

On the other hand, such social ties may be to the detriment of the firm if, for example, socially tied co-workers exert peer pressure on each other to enforce norms of low effort [Roy 1952, Ichino and Maggi 2000, Bandiera et al 2005], workers engage in collusive behavior against the principal [Tirole 1986, Kofman and Lawarree 1993], workers engage in influence activities with managers they are socially tied to [Milgrom 1988], or managers display favoritism towards workers they are socially connected to [Prendergast and Topel 1996]. ${ }^{2}$

In short, the existence of social ties between workers impacts on nearly all aspects of firm and worker behavior, including how workers can be expected to respond to a given set of incentives, the optimal compensations structures for workers at different tiers of the firm hierarchy, and the optimal organizational design of the firm. Taking account of social capital within the firm may therefore help explain differences in the behavior of workers in the same workplace, as well as differences in the structure and performance of otherwise observationally similar firms.

\footnotetext{
${ }^{1}$ Relatedly, Fehr and Fischbacher [2002] provide an overview of the laboratory evidence on social concerns in workplace environments.

${ }^{2}$ Both the positive and negative effects of social connections have been stressed in the organizational behavior and sociology literatures. Examples of such work includes that on the effect of manager-subordinate similarity on subjective outcomes such as performance evaluations, role ambiguity, and job satisfaction [Tsui and O'Reilly 1989, Thomas 1990, Wesolowski and Mossholder 1997], and on how social networks within the firm influence within firm promotions [Podolny and Baron 1997].
} 
In this paper, we first analyze the formation of social capital - as embodied in the network of friendship ties among co-workers - in a leading UK farm producer of soft fruit. We then review evidence from a field experiment we conducted on the farm to highlight one particular mechanism through which social capital significantly affects worker performance [Bandiera et al 2006].

By focusing on social ties within the firm, we build on the previous literature which has emphasized the role that social networks play in enabling individuals to find employment in the first place. In Granovetter's [1974] seminal study, he found the majority of surveyed residents of a Massachusetts town had obtained their jobs through social contacts, a finding confirmed by international comparative evidence [Pellizzari 2004]. There is also evidence of the importance of social networks on the demand side of labor markets such that firms use the social networks of their workers to fill vacancies [Fernandez and Weinberg 1997]. Calvo-Armengol and Jackson [2004] develop a model of social networks in labor markets that makes precise implications for social mobility, patterns of unemployment across demographic groups, and the incentives individuals have to participate in the labor force. We also note that another branch of the literature has shown the importance of the CEO or managerial board of firms being socially connected to those outside of the firm such as local politicians and bureaucrats [Mian and Khwaja 2005].

We use two sources of data for the analysis. The first is a survey we administered to workers to elicit information on their network of friends in the workplace. We first use this to describe the social ties that each worker has to their co-workers, as well as the network of social ties in the firm as a whole. We then present evidence on how friendships form in the workplace. The data allows us to make a distinction between the friendship ties that existed between workers prior to their arrival at the workplace, and those that form in the workplace itself. ${ }^{3}$

The final part of the paper briefly review evidence from a field experiment in the firm in which we exogenously changed managers' incentives from fixed wages to performance pay based on the average productivity of managed workers. The field experiment was designed to shed light on the interplay between social ties, managerial incentives, and workers' performance.

The paper is organized into six sections. Section 2 describes our context and data. Section 3 describes the social ties of workers and the network of ties as a whole. Section 4 presents evidence on the formation of friendships. Section 5 reviews evidence on the interplay between social connections between workers and managers, and the compensation scheme of managers. Section 6 concludes with a discussion of the external validity of our findings.

\footnotetext{
${ }^{3}$ Other studies in economics on the formation of networks include Conley and Udry [2005], Marmaros and Sacerdote [2006], and Mayer and Puller [2007]. Theoretical models of individual incentives to form social links include those using cooperative game theory [Jackson and Wolinksy 1996] and non-cooperative game theory [Bala and Goyal 1999].
} 


\section{Background Information}

\subsection{Organization of the Workplace}

We analyze the formation of social capital in a leading UK farm producer of soft fruit during. Workers are hired from ten Eastern European countries on seasonal contracts and stay between two and six months. To be recruited, individuals must be full-time university students, and have at least one year remaining before graduation. Worker's primary task is to pick fruit, and this takes place over a number of different fields on the farm.

In order to identify any causal effect of social ties on worker's performance, we ideally require there to be underlying factors that drive variation in the social ties that form, but that are plausibly exogenous to worker performance per se. In this specific environment, there exist a number of sources of variation that exogenously restrict the set of social ties that can potentially form. ${ }^{4}$

The first such source arises from the variation in worker nationalities - we would not expect two workers that do not share a common language to report forming friendship ties with each other. Workers are hired from a pool of individuals such that they have similar socioeconomic backgrounds and characteristics. Then conditional on workers being able to communicate with each other, we would expect many social ties to form amongst them. The principle that similarity between individuals on their socioeconomic and behavioral characteristics leads them to be more likely to form social ties with each other, is known as the homophyly principle in the sociology literature. Homophyly has been well documented to be a major driving force in the formation of social ties in a wide range of contexts including friendship, marriage, work advice, information transfer, exchange, and co-membership of organizations [McPherson et al 2001].

A second source of variation stems from the fact that workers arrive to the farm throughout the fruit picking season. This variation is caused by different university term dates in the home countries of workers, and differences in the times when work permits are submitted and issued across individuals. This source of variation implies that workers who have few opportunities to physically interact with each other, are unlikely to form social ties. In addition, upon arrival to the farm, workers attend an induction programme that provides a range of information to workers related to job tasks, health and safety regulations, methods of payment, and local amenities. Hence workers that arrive in close proximity to each other are more likely to attend the same induction program, and therefore are more likely to befriend each other, all else equal.

Third, workers live on the farm site for the entire duration of their stay. They are housed in caravans that accommodate between four and six workers. When workers first arrive, they are allocated to a particular caravan on the basis of - (i) the spaces available in caravans, which

\footnotetext{
${ }^{4}$ Few workers are hired for consecutive seasons and workers are not typically hired from the local labor market.
} 
varies as workers arrive and depart over the season; (ii) the number of individuals that arrive simultaneously, so that if two workers arrive on a given day they are more likely to be housed in a caravan that has two spare places in it than in another caravan, all else equal; (iii) the physical proximity of caravans to fields that are to be picked. The main fields that fruit is picked from on any given day varies over the season because fruit ripens at different times across the fields. ${ }^{5}$

These sources of variation - in worker's nationality, time of arrival on the farm, and the physical location of living quarters - drive the formation of social capital in the firm, and yet may plausibly be exogenous to worker's performance conditional on their observables. This feature of the work environment opens up the possibility of empirically identifying the causal effect of social capital on worker and firm performance. Identifying any such causal relationship in other firm settings may not be as straightforward. While in most firms it is also true that the set of social ties that can potentially form is limited, econometric concerns arise from the fact that the process driving the formation of social ties typically also relates to the underlying forces driving worker and firm performance per se. For example, in many firms workers predominantly interact and form ties with others in the same department or within the same tier of the firm hierarchy, say. However the empirical concern is that the process driving the allocation of workers into departments - either due to the worker's ability, motivation, or past performance, or the ability of managers to identify worker's skill sets - is likely to also drive worker and firm performance directly. ${ }^{6}$

Finally, one countervailing factor in this work environment that may reduce individual incentives to invest into building social ties with others is that compared to the representative firm, worker's tenure is relatively short, lasting for only one fruit picking season. Hence, any long run benefits of social ties such as the reciprocation of favors or cooperation, may be mitigated. However, the fact the workers live and work together on the farm provides many more opportunities for workers to build social ties with others than in the typical firm. This feature of the workplace also provides workers a variety of mechanisms by which to make non-monetary transfers to each other, which may for example, be used to enforce cooperative norms among them. In Section 3 we present descriptive evidence on some forms of non-monetary transfers that take place between friends in our workplace, and the frequency with which such transfers occur. These transfers include going to the supermarket together, eating together, lending/borrowing money, and talking about problems. Moreover, the fact that individuals return to their university in their home

\footnotetext{
${ }^{5}$ Fruit is planted some years in advance so both the fields to be picked in any given season, and the sequence in which they are to be picked, is determined prior to the arrival of workers. There are only a handful of incidences of workers moving across caravans during the season.

${ }^{6}$ To overcome this type of econometric concern, a number of papers have recently exploited natural experiments that lead to the random assignment of peers. For example, Sacerdote [2001] uses such a research strategy to identify the causal effect of peers on student behaviors, and Mas and Moretti [2006] exploit similar methods to identify peer effects on the performance of supermarket cashiers.
} 
countries after the picking season, certainly leaves open the possibility of them realizing the long run benefits of social ties formed during their stay on the farm.

\subsection{Data Sources and Sample Selection}

The main source of information we exploit for the analysis is a survey we administered to workers. This provides data on each workers' socioeconomic background, characteristics, work related attitudes, and self-reported social network of friends on the farm. ${ }^{7}$

To be precise, interviewees were asked to name up to seven of their friends on the farm. For each named friend, workers report whether the social tie existed prior to the individuals arriving to the workplace - which would be the case if for example the individuals are friends from their home university - or whether the friendship newly formed within the workplace. It is important to make the distinction between these two forms of social capital - pre-existing ties and those that form in the workplace. For example, if the number and types of new ties that individuals form within the workplace are shaped by their pre-existing social ties, and if social ties influence behavior within the firm, then the hiring policies of firms should take account of the pre-existing stocks of social capital newly hired workers bring to the firm.

We focus attention on the 2003 survey data as that relates to the year in which the field experiment we later review is based. However, we also report data from the 2004 survey which contains more precise information on the type and frequency of interactions between socially tied workers. This provides insights into the margins along which workers may provide non-monetary transfers to each other. The patterns of such transfers are important to understand because they may well interact with the explicit monetary incentives provided to workers by the firm.

We have found this to be the case in earlier research using data from the 2002 season [Bandiera et al 2005], when workers were paid according to a relative incentive scheme. Under such an incentive scheme, individual effort imposes a negative externality on co-workers' pay. We provide evidence that workers internalize the externality more when the share of their friends in the group of co-workers is larger. We also find that productivity was affected only when workers were able to monitor each other. This supports the hypothesis that under relative incentives, workers were able to sustain implicit collusive agreements, that potentially involve such non-monetary transfers. The results demonstrate the importance of understanding the interplay between social capital in the firm as embodied in friendship ties, and the design of incentive schemes.

As workers continuously arrive to the farm, the worker survey is administered on three different

\footnotetext{
${ }^{7}$ The survey is translated into a number of Eastern European languages, and administered by enumerators from Eastern Europe who did not work at the farm. Workers are generally surveyed around two weeks after their arrival, thus allowing time for new social ties to form and be reported. Each worker is surveyed once.
} 
dates over the peak picking season. The survey is administered in the evening after workers have returned from the fields. We aimed to interview all workers present at the time of the survey. There are three reasons why a worker may not then be interviewed.

First, the worker might arrive and depart between survey dates. This form of non-response is not very prevalent given that surveys are administered approximately every five weeks over the peak picking season. In 2003 for example, less than $10 \%$ of workers spent 35 or fewer days on the farm. Second, on any given survey date, a worker may be present but refuse to answer the survey. Reassuringly, we note that of the workers asked to respond to the survey, over $90 \%$ of them choose to do so. Third, a worker may be present but not respond to the survey because they are not in the living quarters during the evening, when the survey is conducted. This may occur because they are either travelling back from geographically remote fields, or they are engaged in other non-work related activities away from the farm site at the time of the survey.

Some of these types of non-response raise the concern that a non-representative sample of workers may be interviewed. For example, more outgoing or sociable workers may be both more likely to form friendships in the workplace and to be interviewed on any given survey date. This type of sample selection may be especially relevant if we seek to understand the causes and consequences of social capital in the firm.

To address concerns over sample selection, Table A1 presents descriptive evidence on the characteristics of workers that are interviewed and those that are not, for both the 2003 and 2004 surveys. Information available on both sets of workers relate to that contained in personnel records. Two points are of note.

First, those interviewed are similar on observables to those that are not interviewed - in each survey year, the two groups are of similar nationalities, genders, ages, and spend similar amounts of time on the farm. Second, workers are many times more likely to name another surveyed worker as their friend, as they are to name an individual who was not themselves surveyed to be their friend. This is again the case over both survey years. Taken together, this evidence does not suggest interviewed workers are any different to non-interviewed workers in terms of their observable characteristics. $^{8}$

Finally, for the later discussion of the field experiment that relates the productivity of workers to their social ties within the firm, we complement the survey data with the firm's personnel

\footnotetext{
${ }^{8}$ The composition of workers changes slightly over the two years - the percentage of each nationality varies although Poles remain the largest single group, slightly fewer women are hired in 2004, and on average, workers stay on the farm for fewer days in 2004. These differences across years are to be expected given that individuals are not hired for two consecutive years, the pool of individuals hired from varies over years, and the scale and types of farm operation vary from one season to the next. For example there are annual changes in the set of fields picked over the peak season, the quantity and types of fruit available, and the demand for labor related to non-picking tasks, such as planting fruit.
} 
records. In particular, these record each worker's nationality, their time of arrival on the farm, the location of their living quarters, and their productivity. Worker productivity, defined throughout as the kilograms of fruit picked by the worker per hour, is recorded on every field and day they pick fruit. For the field experiment we also exploit the fact that the personnel records identify all co-workers and managers present on each field-day, including those that are not interviewed in our survey.

\section{The Formation of Social Capital}

\subsection{Friendship Ties Among Co-workers}

Table 1a shows the pattern of self-reported friendship ties within the workplace in 2003. There are 879 reported friendships among surveyed workers. As is intuitive, the majority of friendships (57\%) are newly formed in the workplace, and pre-existing friendships are more likely to be reciprocal, namely that if worker $i$ names worker $j$ as a friend, worker $j$ also names worker $i$ as a friend. Conditional on being an old (new) friendship, $70 \%$ (54\%) of friendships are reciprocal.

Table $1 \mathrm{~b}$ shows the proportion of workers that name any given number of friends among their co-workers. The median worker names four other co-workers as their friend, and this rises to five conditional on the worker reporting at least one friendship tie in the firm. However, one in five workers report having no friends among their co-workers, and a similar proportion report seven workers as a friend - the maximum number permitted to be reported. This raises two issues.

First, it may be that some workers, through lack of effort, report having no friends when in truth they do have friends, thus leading to their social network to be underestimated. In relation to this we note that comparing those workers that report no friends in the workplace with those that report at least one, the two groups are of similar nationalities, ages, and spend a similar number of days on the farm in total. There are slight gender differences $-13 \%$ of men report having no friends, whereas the figure for women is $22 \%$. Most importantly however, among those that name at least one friend, they are, on average, themselves named as a friend by 3.11 other surveyed workers. In contrast, among those that name no friends, they are, on average, themselves only named as a friend by 1.25 other workers. This suggests that such workers are indeed more likely to be socially isolated within the firm. The upper graphs in Figure 1 show separately for those that report having no friends, and those that report having at least one, the histogram of the proportion of such workers that are mentioned by others as a friend.

A second concern is that some workers actually have more than seven friends among co-workers

and so their network is underestimated. In relation to this we note that comparing those workers 
that report seven friends with those that report less than seven, the two groups are of similar nationalities, genders, ages, and spend a similar number of days on the farm in total. Most importantly, among those that name seven friends, they are on average themselves named as a friend by 4.23 other surveyed workers. Among those that name less than seven friends, they are on average themselves only named as a friend by 2.41 others. The lower graphs in Figure 1 show separately for those that report having seven friends, and those that report having at most six, the histogram of the proportion of such workers that are mentioned by others as a friend.

Table A2 reports evidence from the 2004 survey on the types and frequency of interactions among workers and their friends in terms of going to the supermarket together, eating together, lending/borrowing money, and talking about problems. This suggests the first reported friend is whom the worker interacts with most frequently along all dimensions, followed by the second reported friend, and so forth. Moreover the first named friend of $i$ is also most likely to themselves report worker $i$ as a friend. Hence although workers may well have more than seven friends in the firm, the strength of the social ties between workers - measured either by the various forms of interaction in Table A2 or the probability the relationship is reciprocal - decreases as they are reported later in the survey.

Reassuringly, the patterns in the data suggest workers do reliably report the number of friends they have in the workplace, and that non-monetary transfers frequently take place between them. The results highlight that the extent to which workers are socially tied to their co-workers varies considerably. While some workers have many social ties to co-workers, others have considerably fewer. For any given number of friendship ties to co-workers, the ratio of newly formed ties to pre-existing ties also varies across workers. On average this ratio is 1.77 although varies from zero to six across all surveyed workers. Finally, at the extreme, some workers are socially isolated within the firm. Of the 300 workers surveyed for example, 24 neither report having no friends nor do any others report them as a friend.

These differences in the number and types of social ties individuals have among their co-workers, and the fact that non-monetary transfers frequently take place between them, can be important sources of variation that explain both the behavior of workers in a given workplace, and also potentially explains differences across firms in their performance. We view collecting information on the social networks within firms as a first stepping stone in a broader research agenda that aims to shed light on how social capital within firms interplays with the organizational features, such as the compensation schemes in place and the nature of tasks carried out in the firm. 


\subsection{Friendship Networks in the Workplace}

Having described the unidirectional friendship ties between a given worker $i$ and her co-workers, we now describe the social network of friendship ties in the firm as a whole. To be precise, consider a scenario in which worker $i$ reports $j$ to be her friend, and $j$ herself reports $k$ as her friend. Workers $i$ and $k$ then lie within the same social network, even though they do not have a direct friendship tie between them. Workers $i$ and $j$ are said to be of distance 1 from each other and workers $i$ and $k$ are of distance 2 from each other. Two workers $i$ and $j$ are then defined to be within the same social network if the distance between them, $d_{i j}$, is finite. ${ }^{9}$

Table 2 describes the characteristics of each friendship network with at least two members. Although there are 14 distinct social networks in the firm, we focus our analysis on the dominant network to which the vast majority of workers belong. While the diameter of the network - the largest distance between any two network members - is 19, the average distance between any two workers is $6.65 .^{10}$ The network comprises an equal number of men and women, and the probability of any two randomly chosen workers in the network being of the same nationality is $17 \%$. Both figures are close to the statistics in the population of workers as a whole, which is as expected given the majority of workers belong to the network.

The remaining statistics describe the network characteristics of the average worker in the network. The degree of a worker is the number of bidirectional friendship ties a worker has namely the number of co-workers that either worker $i$ reports as her friend or vice versa. The average worker is socially tied to 4.47 co-workers, corresponding to $2 \%$ of those in the network. ${ }^{11}$

Finally, we report the local clustering coefficient for workers, which measures how densely interconnected the friends of $i$ are with each other. This is simply the ratio of the actual number of ties that exist between the friends of distance one of worker $i$, to the maximum number of ties that could have existed among them. This coefficient therefore varies from zero to one and the greater the extent of the interconnections of friends of $i$, the higher is the measure of local clustering. For workers in this firm, the local clustering coefficient implies a relatively high incidence of interconnectedness - namely the friends of a given worker $i$ are also likely to be friends with each other. $^{12}$

\footnotetext{
${ }^{9}$ For this analysis we do not therefore consider workers that are not connected to any co-workers.

${ }^{10}$ One of the earliest studies of the properties of large networks, or 'small worlds', is Milgram [1967], in which a sample of individuals were asked to reach a particular target person by passing a message along a chain of acquaintances, which coined the phrase six degrees of separation. Later studies have found similar results. For reviews of the study of large networks see Kochen [1989] and Jackson and Rogers [2004]. Goyal et al [2006] present evidence on the evolution over time in the network of economists.

${ }^{11}$ This figure differs from that in Table 1 because there we reported the number of unidirectional friendship ties that worker $i$ names. In contrast Table 2 describes the social network as a whole using bidirectionally defined friendship ties.

${ }^{12}$ The local clustering coefficient, $c_{i}$, is formally defined as, $c_{i}=\frac{v_{i}}{v^{\max }\left(d_{i}\right)}=\frac{v_{i}}{\frac{1}{2}\left(d_{i}^{2}-d_{i}\right)}$, where $d_{i}$ is the degree of
} 
Figure 2 provides a graphical representation of the social capital in the firm as embodied in the friendship networks of workers. This shows how newly formed friendships in the workplace overlay pre-existing friendship networks to produce the overall network of friendship ties described in Table 2. Figure 2 highlights that - (i) there are many more distinct networks of pre-existing friendships than of newly formed friendships; (ii) the size of pre-existing friendship networks are smaller than for newly formed friendships - the largest sized network of old (new) friends is 21 (166); (iii) pre-existing friendship networks are slightly more interconnected, as measured by the local clustering coefficient, than are newly formed friendships.

While the previous evidence highlighted the variation in the local social ties of workers, this subsection highlights that another source of heterogeneous worker behaviors relates to the worker's position within the network. For example, some workers may be considered to be more focal or influential than others. Identifying such workers may be especially important in understanding the effects of role models and peer effects more generally within firms, or to shed light on the optimal worker the firm should target should it require information to be quickly diffused among co-workers. ${ }^{13}$

\section{The Determinants of Friendship Ties in the Workplace}

\subsection{Descriptive Evidence}

We now turn to understanding the factors driving the formation of friendships in the workplace. To begin with, Table 3 documents the similarity in characteristics of pairs of workers that are socially tied to each other. The first column reports the unconditional probability that a pair of workers $(i, j)$ in which worker $i$ names worker $j$ as a friend, are the same along a given characteristic. The next columns repeat this exercise for pre-existing and newly formed friendships separately. This helps to shed light on whether the underlying motive for forming friendships is different inside and outside of the workplace. Finally, as a benchmark for comparison, the last column reports the same probability among two randomly chosen workers from the workforce.

The first rows in Table 3 show that in terms of socioeconomic characteristics such as gender, nationality, and age, friends are more similar to each other than are two randomly chosen workers. Pre-existing friends tend to be even more similar to each other, especially in terms of their nationality and age, than are newly formed friendships. In line with the discussion in Section

worker $i, v_{i}$ is the actual number of links between the friends of $i$, and $v^{\max }\left(d_{i}\right)=\frac{1}{2}\left(d_{i}^{2}-d_{i}\right)$ is the maximum possible number of links between the friends of $i$ at distance one.

${ }^{13}$ There is a growing theoretical literature on the strategic behavior of agents within network structures. For example, Bloch et al [2005] develop a model of insurance and information exchange within networks. 
2, nationality, time of arrival, and the geographic location in which workers are housed are all significantly more highly correlated within friends than between randomly chosen worker pairs.

The next rows explore how workers' previous employment histories relate to friendship ties. Friends tend to have similar employment histories to each other. For example, they are either both more likely to have had previous paid work before, or to have both not had any previous paid work experience, than two randomly matched workers. However the correlation in this characteristic is not significantly different between pre-existing and newly formed friendships.

An individual attribute that may potentially aid the formation of new friendships in this workplace environment is physical fitness because such workers naturally work at the same speed when picking fruit. While Table 3 shows the correlation in fitness is significantly higher among friends than randomly chosen worker pairs, it is not however significantly different between preexisting and newly formed friendships.

The remaining rows relate to the similarity in work related attitudes among friends. Table A3 presents the questions and potential answers that workers were asked regarding attitudes over various aspects of work. The first two questions relate to factors that motivate workers to work harder - either through winning a prize, or being promoted. The next two questions relate to peer influences, namely whether the worker would pick faster if they worked next to the fastest pickers, or their friends. The next question relates to the compensation scheme workers prefer to be paid under for fruit picking - a fixed wage, a piece rate, or a group based piece rate. Finally, the last question relates to workers preferred group composition if they were to be paid according to a group piece rate - either a group comprising of their friends, or the fastest pickers.

There is considerable heterogeneity across workers in each of these work related attitudes. The single exception relates to how workers would prefer to be paid, where the majority of workers report preferring a fixed hourly wage as opposed to performance related pay.

Table 3 then shows that in terms of attitudes related to worker's motivation, their preferred pay scheme and group composition, friends are more likely to have similar attitudes than randomly chosen workers, although again these differences are not different between pre-existing and newly formed friendships. In contrast, in terms of attitudes over peer influences, the similarity of these attitudes among newly formed friendships are no different than if workers chose their friends at random. Hence although there may well be peer influences of friends on workers behavior, the choice of friends does not appear to itself be driven by attitudes over peer influences themselves.

It is worth noting that these descriptives also shed some light on why homophylic friendships form - this can either be because the costs of meeting similar individuals are low, or because the benefits of forming friendships with similar individuals is high. In this particular setting, the costs of matching with any given worker are relatively similar across all workers. Hence variation in 
the benefits of any given friendship are more likely to drive the formation of ties. Evidence in support of this hypothesis is provided in the final row of Table 3 where we explore the similarity among friends in terms of the university major being studied in their home country. We note the probability that two friends are studying the same major is significantly higher among pre-existing friends than newly formed friends. Pre-existing friends may simply be more likely to match on this characteristic because the costs of meeting others studying the same major in university are low, rather than any intrinsic complementarities of matching with an individual studying the same subject. Indeed in this workplace, workers do not appear to choose their new friends on the basis of this characteristic.

\subsection{Econometric Evidence}

We now provide evidence on whether each of the unconditional correlations among newly formed friendships reported in Table 3 is robust to conditioning on all the dimensions along which workers may be similar, or whether the same underlying trait is being picked up in each case. To do so we define a dummy variable, $l_{i j}$, equal to one if worker $i$ names $j$ as a new friend, and zero if worker $i$ does not name $j$ as a friend and nor are $i$ and $j$ pre-existing friends. The sample is such that there is one observation per pair of workers $(i, j)$ where $i$ and $j$ are both surveyed and are not pre-existing friends. There are 226 workers in the final sample and 50,622 pairs of such workers. This is the set of all possible pairs of new friendships that could have formed in the workplace. We then estimate the following logistic regression,

$$
\operatorname{Pr}\left(l_{i j}=1\right)=\Lambda\left(X_{i j} \beta\right)
$$

where $\operatorname{Pr}\left(l_{i j}=1\right)$ is the probability that $l_{i j}=1, \Lambda($.$) is the logistic CDF, and X_{i j}$ are measures of similarity between $i$ and $j$. The coefficients are presented as log odds ratios with the z-statistic for the test against the null hypothesis that the odds ratio is equal to one, and standard errors are clustered by worker $i$. Table 4 presents the results.

To begin with, Column 1 only controls for the set of characteristics that make it more feasible for workers $i$ and $j$ to form ties - whether they are of the same nationality, live on the same site in the farm, and have overlapped in their stays on the farm for at least two weeks. Along each dimension, the odds ratios are significantly greater than one. For example, worker $i$ is 20 times more likely to report worker $j$ as a newly formed friend if they are of the same nationality, than if they are of different nationalities.

Column 2 additionally controls for the other similarities in socioeconomic characteristics dis-

cussed in Table 3 . The extent to which workers assortatively match into new friendships along 
the lines of nationality, living site, and having overlapped on the farm remain robust to the inclusion of these additional controls. The magnitudes of the estimated odds ratios remain relatively stable over the two specifications, suggesting these dimensions are not much correlated to other dimensions along which workers may be similar. Moreover the odds ratios along these dimensions - which restrict the feasible set of workers friendship ties can reasonably be expected to form with - are orders of magnitude larger than for the other characteristics of worker pairs.

The odds ratios along other dimensions of worker similarity show that workers are not more likely to form new friendships with those of the same gender or age. In terms of previous employment histories, new friends are positively matched on whether they have previously had paid employment, and negatively matched on whether they have had previous experience on a farm or not. This latter result is in line with those workers that have no previous experience of this particular work environment choosing to form friendships with those that have such experience, other things equal.

The specification in Column 3 then additionally controls for the work related attitudes of individuals. We see that - (i) workers are positively assortatively matched in terms of the rewards that would motivate them to work hard; (ii) worker attitudes towards the influence of peers does not drive the formation of new friendships; (iii) workers are more likely to form friendships with others that prefer the same compensation scheme.

In both Columns 2 and 3, the odds of forming a new friendships with others that are studying the same university major are significantly smaller than forming a friendship with someone studying another major. This offers further support to the idea that pre-existing friendships are positively matched along this dimension simply because the costs of meeting individuals on the same university major are significantly lower, rather than there being any intrinsic complementarities in matching with such individuals, once other forms of similarity are conditioned on.

To further explore differences between the formation of new and old friendships, in Column 4 we redefine $l_{i j}$ to be equal to one if worker $i$ reports $j$ as a new friend, and equal to zero if worker $i$ reports $j$ as a pre-existing friend. We therefore drop all worker pairs that are neither pre-existing nor new friends from this specification. The results show that relative to pre-existing friends, newly formed friends in the workplace are significantly less likely to be of the same age, studying the same university major, experienced the same employment history, and are significantly more likely to prefer the same compensation scheme. Workers are not more likely to form new friendships with those of the same level of physical fitness, implying that friendships do not form with those they work at the same speed as, other things equal. 


\subsubsection{Unobserved Worker Heterogeneity}

An econometric concern with the specification in (1) is that there may be unobserved heterogeneity across workers that drives the formation of new friendships. For example, some individuals may naturally be more outgoing or sociable and therefore more likely to form new friendships than others. Such unobserved heterogeneity is unlikely to bias estimates of $\beta$ because whether or not any two workers are similar along a given dimension will be uncorrelated to how sociable or outgoing the reporting worker is. On the other hand, $\beta$ is more likely to be inconsistently estimated if the unobserved heterogeneity relates to the pre-existing network of friends that worker $i$ has. In this case worker $i$ 's incentives to match with others, and whom to match to, may be affected by the characteristics of their existing network. To address this concern we estimate a conditional logit regression where observations are grouped by worker $i$,

$$
\operatorname{Pr}\left(l_{i j}=1\right)=\Lambda\left(X_{i j} \beta+\lambda_{i}\right)
$$

where $\lambda_{i}$ captures unobserved heterogeneity across workers. This can only be estimated among the subsample of workers that report at least one new friend. In this specification we continue to cluster the standard errors by worker $i{ }^{14}$

The result, reported in Column 5 of Table 4, shows most of the estimates of the odds ratios to be very similar to the baseline estimates in Column 3. The only exception to this is that the odds ratio of the workers studying the same university major is now not significantly different from one.

A similar set of concerns relate to unobserved heterogeneity across the workers being matched to - worker $j$. For example, other things equal, workers may all be more likely to report being a friend of worker $j$ if $j$ is particularly outgoing, sociable, or has a valuable social network of friends that $i$ wants to be part of. In other words, there may be some individuals that others want to match to more than others. To address such concerns we estimate the following conditional logit regression where observations are grouped by worker $j$,

$$
\operatorname{Pr}\left(l_{i j}=1\right)=\Lambda\left(X_{i j} \beta+\lambda_{j}\right)
$$

$\lambda_{j}$ captures unobserved heterogeneity across workers being matched to. This can only be estimated for worker $j$ 's that are reported to be neither the friend of no other surveyed worked, nor the friend of all surveyed workers. In this specification we cluster standard errors by worker $j$. Column 6 shows the results to be qualitatively similar to those in the baseline specification in Column 3 . Again once heterogeneity across workers is accounted for, the odds ratio of the workers studying

\footnotetext{
${ }^{14}$ If we estimate (1) and restrict the sample to workers that report at least one new friend, the results are very similar to those reported in Column 3.
} 
the same university major is not significantly different from one.

An alternative approach to controlling for heterogeneity across workers is to condition on the observed heterogeneity across workers $i$ and $j$. For example an older or more experienced worker might be more likely to talk to and befriend others, irrespective of the similarity in their ages. To address this, Column 7 additionally controls for the following characteristics of both $i$ and $j$ - their nationality, living site, arrival date, gender, age, subject being studied, whether they have had paid employment before, worked on a farm before, their self-reported level of physical fitness, and their answer to each of the work related attitude and pay preference questions discussed earlier. Some of these controls are perfect predictors of friendship ties for some workers so the sample drops slightly. Despite the fact that a wide range of observable characteristics of both workers is controlled for, the qualitative results remain similar to those in the baseline specification.

\section{$5 \quad$ Why Social Capital Matters}

We now briefly review recent evidence from Bandiera et al [2006], on one particular mechanism through which social capital matters for the firm. In 2003 we conducted a field experiment in the firm in which we exogenously changed managers' incentives from fixed wages to performance pay based on the average productivity of managed workers. This was designed to shed light on the interplay between social ties, managerial incentives, and workers' performance. ${ }^{15}$

Managers, like workers, are hired on seasonal contracts, and from the same pool of individuals. At the start of the season the firm decides which individuals will be assigned to managerial roles. There are very few instances of workers being promoted to a manager within the season or vice versa. Managers are each assigned a group of around twenty workers, and their logistical tasks include the allocation of workers to rows at the start of the field-day, reallocating workers to new rows once they have finished picking the row they were originally assigned to, and ensuring no bottlenecks form preventing workers from continuing to pick fruit. A key feature of this setting is therefore that managerial effort is complementary to worker effort and can be targeted to individual workers. As workers are paid piece rates, this implies managers can affect a worker's productivity and hence his earnings.

Managers were paid fixed wages in the first half of the season, and then a managerial performance bonus was introduced. The bonus payment was awarded on a field and day if workers' average productivity on the field-day exceeded an exogenously fixed threshold.

\footnotetext{
${ }^{15}$ Methodologically, we provide a contribution in linking the benefits of natural field experiments [Harrison and List 2004] with the insights gained from 'insider econometric' analysis of firms [Ichniowski and Shaw 2003].
} 


\section{$5.1 \quad$ Measuring Social Connections}

As discussed in Section 2, one problem of using self-reported friendships to measure whether a worker is connected to a manager is that such friendships may be endogenous to how managers have treated the worker in the past. To avoid such concerns, we exploit three plausibly exogenous sources of variation that drive the formation of social ties in this workplace setting.

The first measure defines a worker and manager to be connected if they are of the same nationality. For the second measure, we use the fact that on arrival to the farm, individuals are assigned a consecutive worker number. If two individuals have a worker number within the same ten digit window, we define the two to be socially connected through their arrival cohort. The third measure defines two individuals to be socially connected if they live within five caravan numbers of each other. We then combine the information on social connectivity along these three dimensions as follows. We define $c_{i j}=1$ if worker $i$ and manager $j$ are connected along any dimension, and 0 otherwise. If there are $M_{f t}$ managers present on the field-day, the share of managers the worker is connected to on the field-day is,

$$
C_{i f t}=\frac{\sum_{j} c_{i j}}{M_{f t}},
$$

where the summation in the numerator is over all managers $j$ on field-day $f t$.

On most field-days there are between 2 and 4 managers and between 40 and 80 workers present. As we do not have information on the exact matching of workers to managers within a field, we interpret (4) as the probability that worker $i$ is connected to his manager on field-day ft. To compare field-days in which worker $i$ is surely not connected to his manager, to field-days in which he is connected with positive probability, we define a dummy variable $D C_{i f t}$, equal to one if $C_{\text {ift }}>0$, and zero otherwise.

\subsection{Evidence}

Table 5a reports descriptive statistics for the share of managers worker $i$ is linked to on field-day $f t, C_{i f t}$. On average, a worker is socially tied to .433 managers when managers are paid fixed wages. The share is almost identical (.439) when managers are paid performance bonuses. Table 5 a decomposes the overall variation in social ties into that arising within and between workers. At least one third of the overall variation in social connections arises from variation within a worker over field-days, and this is true under both managerial incentive schemes. ${ }^{16}$

Table $5 \mathrm{~b}$ then provides evidence on how workers' productivity varies by their social ties to managers on the field-day as measured by the dummy variable $D C_{i f t}$, and the managerial compensation

\footnotetext{
${ }^{16}$ On average, a worker is socially connected to $31 \%$ of the managers by nationality, to $12 \%$ by living site and to $5 \%$ by arrival cohort.
} 
scheme in place. The first column shows that on average, worker productivity is $6.95 \mathrm{~kg} / \mathrm{hr}$ when workers are managed by individuals they are unconnected to, and their managers are paid a fixed wage. Under the same managerial incentive scheme, the productivity of the same workers significantly rises by $1.31 \mathrm{~kg} / \mathrm{hr}$ to $8.27 \mathrm{~kg} / \mathrm{hr}$ when they are managed by individuals they are socially connected to. From a baseline average productivity of $7.93 \mathrm{~kg} / \mathrm{hr}$ across all worker observations when managers are paid a fixed wage, this difference corresponds to a $17 \%$ increase in the productivity of the same worker when managed by individuals he is socially connected to, relative to himself when managed by individuals he is not socially connected to.

The second column makes the same comparison when managers are paid a performance bonus. On average, the productivity of a worker is no different on field-days when he is socially connected to his managers to field-days when he is socially unconnected to his managers. The unconditional difference-in-difference in workers' productivity by their social connections to managers and across managerial incentive scheme, is $1.20 \mathrm{~kg} / \mathrm{hr}$, and is significantly different from zero. As workers are paid piece rates, differences in worker productivity by social connectivity to managers and managerial incentive scheme translate into similar differences in worker earnings. ${ }^{17}$

These results suggest worker productivity is significantly higher if they are socially connected to their managers, but only when managerial incentives are low powered.

\section{Conclusion}

This paper has presented evidence on the social capital in one particular firm, as embodied in the friendship ties among workers. We describe the structure of the friendship network as a whole and present evidence on the determinants of social ties. Having data from one firm naturally raises issues of the external validity of our results.

The firm we study, as any other, has unique features that shape social connections between workers and managers and their effect on productivity. In particular, in this setting managers and workers are of similar ages and backgrounds, they are predominantly young individuals, and they live on the farm site for the entire duration of their stay. All these features increase the likelihood that they form strong social connections with one another. In other settings, social connections might be less likely to form or to be strong enough to affect behavior. On the other hand, the workers in this study are employed on short term seasonal contracts and so long run social ties

\footnotetext{
${ }^{17}$ Reading across the columns, we note there is a significant increase in productivity moving from a regime in which managers are paid a fixed wage, to when they are paid performance bonuses. This increase corresponds to the effect of the introduction of managerial performance pay, and has been analyzed in detail in Bandiera et al [2007]. It is these benefits of the bonus scheme that made the change in managerial incentives profitable for the firm. Hence the bonus scheme was kept in place by the farm management in later seasons.
} 
are less likely to form relative to other firms.

More generally, in other settings we would expect the existence of social ties between workers to impact on aspects of firm and worker behavior, including how workers respond to a given set of incentives, the optimal compensations structures for workers at different tiers of the firm hierarchy, and the optimal organizational design of the firm. Taking account of social capital within the firm may therefore help explain both differences in the behavior of workers in the same workplace environment, as well as differences in the structure and performance of otherwise observationally similar firms.

Integrating social capital into models of the production function of the firm, may help better reconcile empirical observations with the predictions of economic theory. It has been previously noted in the literature that there is greater variation in compensation contracts than can be explained by standard models of contracting [Baker et al 1988], and that factors such as job design, human resource policies, and participative decision making, all have significant effects on productivity [Ichniowski et al 1997].

A number of steps have been taken in this direction. For example, Ichnioski et al [2003] develop a model that incorporates an organization's 'connective capital' - defined as the stock of human capital that employees can access through their connections to other workers - as an input into its production function. An important implication of this modelling framework is that by forming connections to each other, workers create positive externalities in the information available to other workers. As workers do not internalize these social returns when forming connections, this provides an underlying justification to why firms are observed investing resources into fostering links between workers, such as team building exercises. Similarly, Akerlof and Kranton [2005] discuss how expanding standard models to incorporate the concept of identity can help us to better understand incentives within firms, and the organization of firms.

While these are the first steps, they highlight the challenges and rewards of a research agenda that brings together work from sociology, psychology, anthropology, and management, into economic theories of the firm.

\section{References}

[1] AKERLOF.G.A AND R.E.KRANTON (2005) "Identity and the Economics of Organizations", Journal of Economic Perspectives 19: 9-32.

[2] BAKER.G.P, R.GibBons, And K.J.murphy (1988) "Compensation and Incentives: Theory and Practice", Journal of Finance 43: 593-616. 
[3] BALA.V And S.gOYAl (2000) “A Noncooperative Model of Network Formation", Econometrica 68: 1181-229.

[4] Bandiera.o, i.Barankay, And i.Rasul (2005) "Social Preferences and the Response to Incentives: Evidence From Personnel Data", Quarterly Journal of Economics 120: 917-62.

[5] BANDiERA.O, I.BARANKAy, AND I.RASul (2006) Social Connections and Incentives in the Workplace: Evidence from Personnel Data, mimeo, LSE.

[6] BANDiERA.O, I.BARANKAy, AND I.RASUl (2007) "Incentives for Managers and Inequality Among Workers: Evidence from a Firm Level Experiment", Quarterly Journal of Economics 122: $729-73$.

[7] Barnard.c (1938) The Functions of the Executive, Cambridge: Harvard University Press.

[8] BeWley.t.F (1999) Why Wages Don't Fall During a Recession, Cambridge: Harvard University Press.

[9] BLOCh.F, G.Genicot, AND D.RAy (2005) Informal Insurance in Social Networks, mimeo New York University.

[10] Calvo-Armengol. A And M.o.Jackson (2004) "The Effects of Social Networks On Employment and Inequality", American Economic Review 94: 426-54.

[11] Conley.t.g And C.R.udry (2005) "Social Networks in Ghana", in C.B.Barrett (ed,), The Social Economics of Poverty: Identities, Groups, Communities and Networks, London: Routledge.

[12] Encinosa.W.E, M.S.gaynor And J.B.Rebitzer (1997) The Sociology of Groups and the Economics of Incentives: Theory and Evidence on Compensation Systems, NBER Working Paper 5953.

[13] FeHR.E AND U.Fischbacher (2002) "Why Social Preferences Matter - The Impact of NonSelfish Motives on Competition, Cooperation and Incentives", Economic Journal 112: C1C33.

[14] FEHR.E AND J.A.LIST (2004) "The Hidden Costs and Returns of Incentives - Trust and Trustworthiness Among CEOs", Journal of the European Economic Association 2: 1-29.

[15] Fernandez.R.m And N.Weinberg (1997) "Sifting and Sorting: Personal Contacts and Hiring in a Retail Bank", American Sociological Review 62: 883-902. 
[16] GOYAl.S, M.VAn Der LeiJ, And J.L.moragA-GOnZAlez (2006) "Economics: An Emerging Small World?", Journal of Political Economy 114: .403-12.

[17] Granovetter.m (1974) Getting a Job, University of Chicago Press: Chicago.

[18] Hamilton.B.H, J.A.nickerson, And H.oWAn (2003) "Team Incentives and Worker Heterogeneity: An Empirical Analysis of the Impact of Teams on Productivity and Participation", Journal of Political Economy 111: 465-97.

[19] HARRISON.G AND J.LIST (2004) "Field Experiments", Journal of Economic Literature 152: 1009-55.

[20] HAYES.R, P.OYER, AND S.SCHAEFER (2006) "Co-worker Complementarity and the Stability of Top Management Teams", Journal of Law, Economics, and Organization 22: 184-212.

[21] ICHinO.A AND G.MAGGi (2000) "Work Environment and Individual Background: Explaining Regional Shirking Differentials in a Large Italian Firm", Quarterly Journal of Economics 115: 1057-90.

[22] ICHNIOWSKI.C AND K.L.SHAW (2003) "Beyond Incentive Pay: Insiders' Estimates of the Value of Complementary Human Resource Management Practices", Journal of Economic Perspectives 17: 155-78.

[23] ICHniowski.C AND K.L.SHAW (2005) Connective Capital: Building Problem-Solving Networks Within Firms, mimeo, Stanford University.

[24] ICHniowski.C, G.Prennushi, And K.L.SHAW (1997) "The Effects of Human Resource Management Practices on Productivity", American Economic Review 86: 291-313.

[25] Jackson.m.o And A.Wolinsky (1996) "A Strategic Model of Social and Economic Networks", Journal of Economic Theory 71: 44-74.

[26] Jackson.m.o And B.w.rogers (2005) "The Economics of Small Worlds, Journal of the European Economic Association 3: 617-27.

[27] Jones.D And T.Kato (1995) "The Productivity Effects of Employee Stock-Ownership Plans and Bonuses: Evidence from Japanese Panel Data", American Economic Review 85: 391-414.

[28] KAndel.E AND E.LAzear (1992) "Peer Pressure and Partnerships", Journal of Political Economy 100: 801-13. 
[29] KNEZ.M, AND D.Simester (2001) "Firm-Wide Incentives and Mutual Monitoring at Continental Airlines", Journal of Labor Economics 19: 743-72.

[30] Kochen.m (1989) The Small World, Ablex, Norwood: New Jersey.

[31] Kofman.F And J.LAWArree (1993) "Collusion in Hierarchical Agency", Econometrica 61: 629-56.

[32] LAzEAR.E.P (1989) "Pay Equality and Industrial Politics", Journal of Political Economy 97: $561-80$.

[33] Marmaros.D And B.SACERdote (2006) "How Do Friendships Form?", Quarterly Journal of Economics 121: 79-119.

[34] Marshall.a (1890) Principles of Economics, Macmillan and Co.: London.

[35] MAS.A And E.moretti (2006) Peers at Work, mimeo, University of California, Berkeley.

[36] MAYER.A AND S.L.Puller (2007) The Old Boy (and Girl) Network: Social Network Formation on University Campuses, mimeo, Texas A\&M.

[37] Mayo.e (1933) The Human Problems of an Industrial Civilization, New York: Macmillan.

[38] MCPherson.m, L.Smith-Lovin, And J.m.COOK (2001) "Birds of a Feather: Homophily in Social Networks", Annual Review of Sociology 27: 415-44.

[39] Mian.A.R AND A.I.Khwaja (2005) "Do Lenders Favor Politically Connected Firms? Rent Provision in an Emerging Financial Market", Quarterly Journal of Economics 120: 1371-1411.

[40] Milgram.s (1967) "The Small World Problem", Psychology Today 2: 60-7.

[41] Milgrom.P.R (1988) "Employment Contracts, Influence Activities, and Efficient Organization Design", Journal of Political Economy 96: 42-60.

[42] Pellizzari.m (2004) Do Friends and Relatives Really Help in Getting a Good Job? CEP Discussion Paper 623.

[43] Podolny.J.m And J.N.BARon (1997) "Resources and Relationships: Social Networks and Mobility in the Workplace", American Sociological Review 62: 673-93.

[44] PRendergast.C AND R.H.topel (1996) "Favoritism in Organizations", Journal of Political Economy 104: 958-78. 
[45] Roethlisberger.F.J And W.DiCkson (1939) Management and the Worker, Cambridge: Harvard University Press.

[46] Rotemberg.J.J (1994) "Human Relations in the Workplace", Journal of Political Economy 102: $684-717$.

[47] ROY.D (1952) "Quota Restriction and Goldbricking in a Machine Shop", American Journal of Sociology 57: 427-42.

[48] Sacerdote.B (2001), "Peer Effects With Random Assignment: Results for Dartmouth Roommates", Quarterly Journal of Economics 116: 681-704.

[49] TiRole.J (1986) "Hierarchies and Bureaucracies: On the Role of Collusion in Organizations", Journal of Law, Economics and Organizations 2: 181-214.

[50] Thomas.D.A (1990) "The Impact of Race on Managers' Experiences of Developmental Relationships", Journal of Organizational Behavior 11: 479-92.

[51] TSUi.A.S AND C.A.oreilly (1989) "Beyond Simple Demographic Effects: The Importance of Relational Demography in Superior-Subordinate Dyads", Academy of Management Journal 32: 402-23.

[52] Wesolowski.m.a And K.W.mossholder (1997) "Relational Demography in SupervisorSubordinate Dyads: Impact on Subordinate Job Satisfaction, Burnout, and Perceived Procedural Justice", Journal of Organizational Behavior 18: 351-62. 
Table 1a: The Number and Type of Friendships in the Workplace

\begin{tabular}{cccc} 
& All Friends & $\begin{array}{c}\text { Pre-existing } \\
\text { Friends }\end{array}$ & $\begin{array}{c}\text { Newly Formed } \\
\text { Friends }\end{array}$ \\
\hline Number of friendships & 829 & 359 & 471 \\
Number of reciprocal friendships & 504 & 252 & 252 \\
\hline
\end{tabular}

Table 1b: Distribution of Number of Friends, by Friendship Type

\begin{tabular}{cccc} 
Number of friendships & All Friends & $\begin{array}{c}\text { Pre-existing } \\
\text { Friends }\end{array}$ & $\begin{array}{c}\text { Newly Formed } \\
\text { Friends }\end{array}$ \\
\hline $\mathbf{0}$ & 17.7 & 18.6 & 22.9 \\
$\mathbf{1}$ & 7.70 & 34.6 & 11.3 \\
$\mathbf{2}$ & 5.00 & 12.6 & 14.3 \\
$\mathbf{3}$ & 10.3 & 12.1 & 16.9 \\
$\mathbf{4}$ & 13.0 & 7.4 & 13.0 \\
$\mathbf{5}$ & 14.3 & 6.93 & 8.66 \\
$\mathbf{6}$ & 11.7 & 3.46 & 9.52 \\
$\mathbf{7}$ & 20.3 & 4.33 & 3.46 \\
\hline Median & 4 & 1 & 3 \\
Mean & 3.85 & 2.11 & 2.67 \\
Standard deviation & 2.50 & 1.94 & 2.11 \\
\hline
\end{tabular}

Conditional on at least one reported friendship

$\begin{array}{cccc}\text { Median } & 3 & 2 & 5 \\ \text { Mean } & 4.67 & 2.60 & 3.46 \\ \text { tandard deviation } & 1.93 & 1.84 & 1.74\end{array}$

Notes: This information is obtained from the 2003 worker questionnaire in which 300 workers were surveyed. Each worker was asked to list up to seven of their friends in the workplace. A "pre-existing" friend is defined to be an individual that was known before arriving to the workplace, and a "newly formed" friend is defined as a friendship tie that forms at the workplace. A reciprocal friendship is one in which worker i names worker $j$ as a friend and vice versa. Table 1a reports the number of friendship ties reported between workers in the survey. Table $1 \mathrm{~b}$ reports the proportion of all surveyed workers that report any given number of friends $(0$ to 7) by friendship type. 
Table 2: Characteristics of Friendship Networks

Mean, standard errors in parentheses, and 95\% confidence interval in brackets.

\section{Network Level Statistics}

\begin{tabular}{|c|c|c|c|c|c|c|c|}
\hline Size & Frequency & Diameter & $\begin{array}{l}\text { Average } \\
\text { Distance }\end{array}$ & $\begin{array}{l}\text { Same } \\
\text { Gender }\end{array}$ & $\begin{array}{c}\text { Same } \\
\text { Nationality }\end{array}$ & Degree & Local Clustering Coefficient \\
\hline \multirow[t]{3}{*}{231} & 1 & 19 & 6.65 & 0.50 & 0.17 & 4.47 & .764 \\
\hline & & & & & & $(0.15)$ & $(.013)$ \\
\hline & & & & & & {$[4.17,4.76]$} & {$[.738, .791]$} \\
\hline \multirow[t]{3}{*}{9} & 1 & 2 & 1.33 & 0.61 & 0.44 & 5.33 & .926 \\
\hline & & & & & & $(0.53)$ & $(.049)$ \\
\hline & & & & & & {$[4.12,6.55]$} & {$[.813,1.04]$} \\
\hline \multirow[t]{3}{*}{5} & 2 & 1.5 & 1.15 & 0.40 & 0.65 & 3.4 & .970 \\
\hline & & & & & & $(0.31)$ & $(.030)$ \\
\hline & & & & & & {$[2.71,4.09]$} & {$[.902,1.04]$} \\
\hline \multirow[t]{3}{*}{4} & 1 & 1 & 1 & 0.50 & 1 & 3 & 1 \\
\hline & & & & & & $(0)$ & $(0)$ \\
\hline & & & & & & {$[3,3]$} & {$[1,1]$} \\
\hline \multirow[t]{3}{*}{3} & 2 & 2 & 1.33 & 0.67 & 1 & 1.33 & .889 \\
\hline & & & & & & $(0.21)$ & $(.070)$ \\
\hline & & & & & & {$[0.79,1.88]$} & {$[.708,1.07]$} \\
\hline 2 & 7 & 1 & 1 & 0.86 & 0.86 & 1 & 1 \\
\hline
\end{tabular}

Notes: This information is obtained from the 2003 worker questionnaire in which 300 workers were surveyed, and includes all non-interviewed workers that are named as the friend of at least one interviewed worker. We define two workers that are directly connected to be of distance one to each other. The size of the network is then the number of workers in the network that are linked at some finite distance to each other. The diameter of the network is the longest distance between two workers that exists in a network. Same gender and same nationality refer to the proportion of workers in the network that are of the same gender or nationality. The degree of a worker is the number of friendship links the worker has. The local clustering coefficient measures how densely interconnected the friends of a given worker are to each other. 
Table 3: Unconditional Probabilities Among Friends, by Friendship Type

Means, standard errors in parentheses, and 95\% confidence interval in brackets

\begin{tabular}{|c|c|c|c|c|}
\hline & All Friends & $\begin{array}{l}\text { Pre-existing } \\
\text { Friends }\end{array}$ & $\begin{array}{l}\text { Newly Formed } \\
\text { Friends }\end{array}$ & $\begin{array}{c}\text { Randomly } \\
\text { Matched Workers }\end{array}$ \\
\hline \multirow[t]{3}{*}{ Same gender } & .622 & .610 & .632 & .498 \\
\hline & $(.020)$ & $(.028)$ & $(.026)$ & $(.0002)$ \\
\hline & {$[.583, .661]$} & {$[.557, .664]$} & {$[.580, .684]$} & {$[.498, .499]$} \\
\hline \multirow[t]{3}{*}{ Same nationality } & .890 & .969 & .830 & .206 \\
\hline & $(.014)$ & $(.013)$ & $(.022)$ & $(.007)$ \\
\hline & {$[.862, .919]$} & {$[.943, .995]$} & {$[.787, .873]$} & {$[.192, .221]$} \\
\hline \multirow[t]{3}{*}{ Same age } & .381 & .510 & .283 & .223 \\
\hline & $(.020)$ & $(.030)$ & $(.024)$ & $(.005)$ \\
\hline & {$[.341, .421]$} & {$[.450, .569]$} & {$[.236, .330]$} & {$[.214, .233]$} \\
\hline \multirow[t]{3}{*}{ Same date of arrival } & .570 & .674 & .490 & .050 \\
\hline & $(.025)$ & $(.034)$ & $(.032)$ & $(.002)$ \\
\hline & {$[.521, .618]$} & {$[.607, .741]$} & {$[.427, .554]$} & {$[.045, .055]$} \\
\hline \multirow[t]{3}{*}{ Same living site } & .932 & .944 & .923 & .516 \\
\hline & $(.012)$ & $(.016)$ & $(.016)$ & $(.016)$ \\
\hline & {$[.908, .955]$} & {$[.912, .976]$} & {$[.891, .954]$} & {$[.484, .548]$} \\
\hline \multirow[t]{3}{*}{ Both have done paid work before or not } & .817 & .840 & .800 & .704 \\
\hline & $(.021)$ & $(.026)$ & $(.026)$ & $(.014)$ \\
\hline & {$[.777, .858]$} & {$[.790, .891]$} & {$[.749, .851]$} & {$[.676, .733]$} \\
\hline \multirow[t]{3}{*}{ Both have worked on a farm before or not } & .761 & .816 & .721 & .652 \\
\hline & $(.021)$ & $(.028)$ & $(.028)$ & $(.014)$ \\
\hline & {$[.720, .803]$} & {$[.761, .871]$} & {$[.667, .776]$} & {$[.625, .679]$} \\
\hline \multirow[t]{3}{*}{ Same reported level of physical fitness } & .599 & 608 & .592 & .484 \\
\hline & $(.022)$ & $(.029)$ & $(.028)$ & $(.008)$ \\
\hline & {$[.556, .642]$} & {$[.550, .666]$} & {$[.535, .648]$} & {$[.467, .500]$} \\
\hline \multirow[t]{3}{*}{ Same answer on "pick faster if could win a prize" } & .408 & .460 & .369 & .234 \\
\hline & $(.022)$ & $(.033)$ & $(.025)$ & $(.004)$ \\
\hline & {$[.364, .452]$} & {$[.395, .526]$} & {$[.320, .419]$} & {$[.226, .243]$} \\
\hline \multirow[t]{3}{*}{ Same answer on "pick faster if could be promoted" } & .362 & .405 & .331 & .235 \\
\hline & $(.022)$ & $(.030)$ & $(.027)$ & $(.004)$ \\
\hline & {$[.319, .406]$} & {$[.346, .464]$} & {$[.278, .384]$} & {$[.227, .243]$} \\
\hline \multirow[t]{3}{*}{ Same answer on "pick faster if nearby fast pickers" } & .305 & .355 & .267 & .237 \\
\hline & $(.017)$ & $(.027)$ & $(.022)$ & $(.005)$ \\
\hline & {$[.271, .339]$} & {$[.302, .407]$} & {$[.222, .311]$} & {$[.228, .246]$} \\
\hline \multirow[t]{3}{*}{ Same answer on "pick faster if nearby friends" } & .271 & .327 & .231 & .231 \\
\hline & $(.018)$ & $(.026)$ & $(.025)$ & $(.004)$ \\
\hline & {$[.235, .307]$} & {$[.275, .379]$} & {$[.182, .280]$} & {$[.223, .238)$} \\
\hline \multirow[t]{3}{*}{ Same answer on "preferred pay scheme" } & .713 & .704 & .720 & .601 \\
\hline & $(.022)$ & $(.030)$ & $(.027)$ & $(.014)$ \\
\hline & {$[.670, .756]$} & {$[.645, .763]$} & {$[.667, .774]$} & {$[.574, .628]$} \\
\hline \multirow[t]{3}{*}{ Same answer on "preferred group composition" } & .552 & .585 & .526 & .408 \\
\hline & $(.023)$ & $(.031)$ & $(.029)$ & $(.008)$ \\
\hline & {$[.508, .597]$} & {$[.523, .647]$} & {$[.469, .583]$} & {$[.391, .424]$} \\
\hline \multirow[t]{3}{*}{ Same university major being studied } & .399 & .609 & .234 & .201 \\
\hline & $(.022)$ & $(.032)$ & $(.024)$ & $(.007)$ \\
\hline & {$[.356, .442]$} & {$[.544, .673]$} & {$[.186, .281]$} & {$[.189, .214]$} \\
\hline
\end{tabular}

Notes: Exactly half the workers are male. There are 10 nationalities of worker, the largest being Poles who comprise $34 \%$ of all workers, followed by Ukrainians (26\%) and Bulgarians (12\%). Workers are aged between 20 and 25, and they arrive to the workplace between April and August. The median worker arrives in May. There are four sites on the farm in which workers can potentially reside. This is used to build to the 'same living site' variable. Workers were asked to report their physical fitness as compared to the average person of their age on a seven point scale where one corresponds to well above average and seven corresponds to well below average. This is used to build the 'same physical fitness' variable. The work related preference questions are as follows. First, workers were asked if they agree strongly/agree/indifferent/disagree/disagree strongly, with the statements, "I would pick faster if I could win a prize as a result", "I would pick faster if I could be promoted ts supervisor" "I would pick faster if I worked next to the fastest pickers", and "I would pick faster if I worked next to my friends". Second, workers were asked about their preferred pay scheme in the following way - "how would you like to be paid for your work on the farm?" They could provide one of the following answers - (i) a fixed hourly pe; (ii) varia wage, (I)

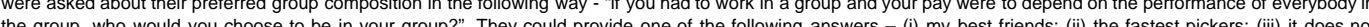
the group, who would you ches $(17 \%)$ 


\section{Table 4: The Formation of Social Ties in the Workplace}

Dependent Variables --

Columns 1 to 3,5 to 7 : Equals 1 if worker $i$ reports $j$ as a new friend, 0 if otherwise and the workers are not old friends

Column 4: Equals 1 if worker $i$ reports $j$ as a new friend, 0 if worker $i$ reports $j$ as a pre-existing friend

Log odds ratios reported, standard errors clustered by worker i in Columns 1 to 5 and 7 , by worker $j$ in Column 6

\begin{tabular}{|c|c|c|c|c|c|c|c|}
\hline & $\begin{array}{c}\text { Feasible Ties } \\
\text { (1) } \\
\end{array}$ & $\begin{array}{c}\text { Similarity } \\
\text { (2) } \\
\end{array}$ & $\begin{array}{c}\text { Work Related } \\
\text { Preferences } \\
\text { (3) } \\
\end{array}$ & $\begin{array}{l}\text { New Versus } \\
\text { Old Friends } \\
\text { (4) } \\
\end{array}$ & $\begin{array}{c}\text { Unobserved } \\
\text { Heterogeneity } \\
\text { Among Worker i } \\
\text { (5) } \\
\end{array}$ & $\begin{array}{c}\text { Unobserved } \\
\text { Heterogeneity } \\
\text { Among Worker j } \\
\text { (6) }\end{array}$ & $\begin{array}{c}\text { Observed Heterogeneity } \\
\text { Among Workers i and j } \\
\text { (7) }\end{array}$ \\
\hline \multirow[t]{2}{*}{ Same nationality } & $20.2^{\star \star \star}$ & $16.5^{\star \star \star}$ & $15.6^{\star \star \star}$ & .437 & $17.9^{\star \star \star}$ & $26.8^{\star \star \star}$ & $34.3^{\star \star \star \star}$ \\
\hline & (3.79) & (3.11) & (2.94) & (.301) & (3.38) & (8.78) & (8.36) \\
\hline \multirow[t]{2}{*}{ Same living site } & $15.3^{\star \star \star}$ & $12.0^{\star \star \star}$ & $11.4^{\star \star \star}$ & 1.18 & $11.3^{\star \star \star}$ & $32.5^{\star \star \star}$ & $23.0^{\star \star \star *}$ \\
\hline & (4.44) & (3.59) & (3.44) & (.666) & (3.42) & (10.8) & (7.41) \\
\hline \multirow[t]{2}{*}{ Overlapped for at least two weeks on the farm } & $15.7^{\star \star \star}$ & $9.95^{\star \star}$ & $10.2^{\star \star}$ & 1.42 & $8.52^{\star \star}$ & $6.77^{\star}$ & $10.3^{\star \star}$ \\
\hline & (16.0) & (10.1) & (10.3) & (1.28) & (8.68) & (7.42) & (11.7) \\
\hline \multirow[t]{2}{*}{ Same arrival date } & & $9.15^{\star \star \star}$ & $9.10^{\star \star \star}$ & .659 & $9.17^{\star \star \star}$ & $9.77^{\star \star \star}$ & $10.7^{\star \star \star}$ \\
\hline & & (.156) & (1.58) & (.187) & (1.66) & $(2.01)$ & (2.09) \\
\hline \multirow[t]{2}{*}{ Same gender } & & 1.09 & 1.21 & 1.38 & 1.26 & $1.28^{*}$ & 1.21 \\
\hline & & (.154) & (.179) & (.321) & (.197) & (.189) & (.208) \\
\hline \multirow[t]{2}{*}{ Same age } & & .939 & .923 & $.398^{\star \star \star}$ & 1.03 & .916 & .991 \\
\hline & & (.149) & (.151) & (.090) & (.164) & (.158) & (.168) \\
\hline \multirow[t]{2}{*}{ Same university major being studied } & & $.665^{\star \star}$ & $.697^{\star \star}$ & $.182^{\star \star \star}$ & .791 & .956 & .825 \\
\hline & & (.116) & (.124) & $(.048)$ & (.144) & (.183) & (.170) \\
\hline \multirow[t]{2}{*}{ Both have done paid work before or not } & & $2.04^{\star \star \star}$ & $1.97^{\star \star \star}$ & $.535^{*}$ & $1.64^{\star \star}$ & $1.43^{*}$ & 1.08 \\
\hline & & (.444) & (.427) & (.174) & (.328) & (.306) & $(.320)$ \\
\hline \multirow{2}{*}{ Both have worked on a farm before or not } & & $.592^{\star \star \star}$ & $.680^{\star \star}$ & .647 & $.551^{\star \star \star}$ & .744 & $.632^{\star \star}$ \\
\hline & & (.105) & (.126) & (.193) & (.090) & (.153) & (.133) \\
\hline \multirow[t]{2}{*}{ Same reported level of physical fitness } & & $1.38^{\star \star}$ & $1.31^{\star}$ & .990 & $1.41^{\star \star}$ & $1.54^{\star \star \star}$ & $1.53^{\star *}$ \\
\hline & & $(.218)$ & (.205) & (.243) & $(.222)$ & (.236) & (.262) \\
\hline \multirow[t]{2}{*}{ Same answer on "pick faster if could win a prize" } & & & $1.53^{\star \star \star}$ & .668 & $1.74^{\star \star \star}$ & $1.72^{\star \star \star}$ & 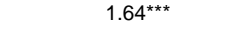 \\
\hline & & & (.229) & (.171) & $(.269)$ & (.301) & (.276) \\
\hline \multirow{2}{*}{ Same answer on "pick faster if could be promoted" } & & & $1.38^{\star \star}$ & .858 & $1.38^{\star}$ & $1.61^{\star \star \star}$ & $1.39^{*}$ \\
\hline & & & (.225) & (.219) & $(.242)$ & (.266) & $(.256)$ \\
\hline \multirow[t]{2}{*}{ Same answer on "pick faster if nearby fast pickers" } & & & .931 & $.686^{\star}$ & 1.03 & 1.11 & 1.12 \\
\hline & & & (.143) & (.158) & (.164) & (.214) & (.202) \\
\hline \multirow[t]{2}{*}{ Same answer on "pick faster if nearby friends" } & & & 1.18 & .921 & 1.27 & .980 & .918 \\
\hline & & & (.211) & (.242) & (.239) & (194) & (.164) \\
\hline \multirow[t]{2}{*}{ Same answer on "preferred pay scheme" } & & & $1.69^{\star \star \star}$ & $2.51^{\star \star \star}$ & $1.83^{\star \star \star}$ & $1.41^{*}$ & $2.00^{\star \star \star}$ \\
\hline & & & $(.285)$ & (.773) & $(.327)$ & (.287) & (.407) \\
\hline \multirow[t]{2}{*}{ Same answer on "preferred group composition" } & & & 1.25 & .799 & 1.24 & 1.11 & 1.24 \\
\hline & & & (.191) & (.184) & (.193) & $(.222)$ & (.211) \\
\hline Observations [worker i - worker j pairs] & 50622 & 50622 & 50622 & 500 & 27337 & 28451 & 49276 \\
\hline
\end{tabular}

Notes: *** denotes that the log odds ratio is significantly different from one at $1 \%$, ** at $5 \%$, and * at $10 \%$. In Columns 1 to 4 , logit regressions are estimated. In Column 5 (6) a conditional logit regression is estimated where observations are grouped by worker i $i$ ). The dependent variable in Columns 1 to $3,5,6$, and 7 is a dummy variable equal to one if worker $i$ reports worker $j$ as being a newly formed friend in the workplace, and zero if otherwise and worker $j$ is not a pre-existing arriving in the workp in Columns 1 to 5 , standard errors are clustered by worker $i$. In Column 6 , standard errors are clustered by worker $j$. In Column 7 we additionally control for each of the characteristics of worker $i$ and $j$ themselves. The "overlapped for at least two weeks on the farm" is derived from the worker i and j's dates of arrival and departure obtained from the firm's personnel records. See Table 3 for definitions of all other controls. 
Table 5a: Social Ties Between Workers and Managers

All observations are at the worker-field-day level

Means, standard deviation between workers in parentheses, and standard deviation within worker in brackets

Managerial Incentive Scheme

Fixed Wages

Share of managers connected to $i\left(C_{i f t}\right)$

\section{.433}

(.303)

[.193]
Performance Bonus

Table 5b: Worker Productivity (kg/hr), by Social Ties to Managers and Managerial Incentive Scheme

Means, standard errors in parentheses

Managerial Incentive Scheme

Fixed Wages

Performance Bonus

Unconnected on field-day $\left(\mathrm{DC}_{\mathrm{ift}}=\mathbf{0}\right)$

Connected on field-day $\left(\mathrm{DC}_{\mathrm{ift}}=1\right)$

6.95

8.27

(.244)

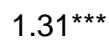

(.257)
9.11

(.568)

9.23

(.702)

Notes: ${ }^{* \star}$ denotes significance at $1 \%,{ }^{*}$ at $5 \%$, and ${ }^{\star}$ at $10 \%$. All variables are defined at the worker-field-day level. A manager and worker are defined to be resident in the same living area if they live within five caravans from each other on the farm. A manager and worker are defined to be in the same arrival cohort if they have identification numbers within the same ten digit window. A manager and given worker $i$ are defined to be socially tied if they are either of the same nationality, live in the same area, or are in the same arrival cohort. Each statistic is based on those workers that are tied to at least one manager along at least one of the three dimensions. same area, or are in the same arrival cohort. Each statistic is based on those workers that are tied to at least one manager along at least one of the three dimensions.
There are 267 such workers when managers are paid fixed wages, and 212 such socially tied workers when managers are paid a performance bonus. Overall there are 7818 worker-field-day observations when managers are paid fixed wages, and 4469 worker-field-day observations when managers are paid a performance bonus. In Table 5b, productivity is measured as the number of kilograms of fruit picked per hour by the worker on the field-day. A worker is defined to be unconnected on the field day if she is not socially connected to any of her managers that field-day. A worker is defined to be connected on the field-day if she is socially connected to at least one of her managers. The standard errors on the differences are estimated from running the corresponding least squares regression, allowing the standard errors to be clustered by worker. 
Table A1: Characteristics of Interviewees and Non Interviewees

\section{Sample}

Interviewees Non Interviewees

Number of workers

First nationality

Second nationality

Third nationality

Percentage female

Age (years)

Days on farm

$\begin{array}{cc}300 & 309 \\ \text { Polish (34\%) } & \text { Polish (39\%) } \\ \text { Ukrainian (26\%) } & \text { Ukrainian (21\%) } \\ \text { Bulgarian (12\%) } & \text { Bulgarian (6\%) } \\ 50.3 & 45.8 \\ 21.9 & 22.2 \\ 95.6 & 90.8 \\ 2.78 & 1.02 \\ (2.21) & (1.64)\end{array}$

Number of times mentioned as a

friend by interviewees

$(2.21)$

\begin{tabular}{cc}
\multicolumn{2}{c}{ 2004 Sample } \\
Interviewees & Non Interviewees \\
\hline 289 & 270 \\
Polish (55.4\%) & Polish (56.7\%) \\
Bulgarian (16.6\%) & Ukrainian (12.2\%) \\
Ukrainian (15.6\%) & Bulgarian (10.7\%) \\
45.3 & 42.2 \\
22.1 & 21.9 \\
68.1 & 61.8 \\
1.96 & .452 \\
$(1.65)$ & $(.922)$
\end{tabular}

Notes: This data, with the exception of the number of times mentioned as a friend by respondents, is obtained from the firm's personnel records. The mean and standard deviation (in parentheses) are reported for the number of times mentioned by a friend by respondents. The days on farm is defined to be the number of days between the day on which the individual arrives at the workplace and their date of departure. 
Table A2: The Strength of Ties by Reported Friendship Number

Frequency of Interaction by Activity and Friendship Number (percentage)

\begin{tabular}{|c|c|c|c|c|c|c|c|c|c|c|c|c|c|c|}
\hline \multirow[b]{2}{*}{$\begin{array}{l}\text { Friendship } \\
\text { Number }\end{array}$} & \multirow[b]{2}{*}{$\begin{array}{l}\text { Old } \\
\text { Friend }\end{array}$} & \multirow[b]{2}{*}{$\begin{array}{l}\text { Reciprocal } \\
\text { Friend }\end{array}$} & \multicolumn{3}{|c|}{ Go to Supermarket Together } & \multicolumn{3}{|c|}{ Eat Together } & \multicolumn{3}{|c|}{ Lend/Borrow Money } & \multicolumn{3}{|c|}{ Talk About Problems } \\
\hline & & & Never & Sometimes/Often & Always & Never & Sometimes/Often & Always & Never & Sometimes/Often & Always & Never & Sometimes/Often & Always \\
\hline 1 & 63.8 & 54.3 & 24.8 & 31.1 & 44.0 & 24.1 & 31.6 & 44.3 & 35.9 & 34.4 & 29.7 & 27.1 & 27.5 & 45.4 \\
\hline 2 & 42.8 & 43.3 & 24.7 & 44.4 & 30.9 & 32.8 & 35.7 & 31.0 & 44.2 & 34.4 & 20.8 & 27.4 & 43.6 & 29.1 \\
\hline 3 & 38.9 & 37.7 & 30.5 & 49.4 & 20.1 & 34.7 & 42.3 & 21.8 & 47.0 & 39.6 & 12.7 & 29.5 & 47.0 & 23.5 \\
\hline 4 & 33.1 & 24.4 & 25.0 & 55.4 & 19.6 & 32.1 & 42.5 & 24.5 & 50.5 & 39.6 & 8.91 & 27.9 & 49.6 & 22.5 \\
\hline 5 & 38.0 & 18.3 & 30.0 & 60.0 & 10.0 & 50.0 & 19.6 & 12.5 & 73.2 & 37.5 & 7.14 & 37.1 & 43.6 & 19.4 \\
\hline 6 & 40.7 & 16.7 & 21.3 & 55.3 & 23.4 & 43.5 & 45.6 & 10.9 & 62.2 & 24.4 & 11.1 & 28.3 & 45.6 & 26.1 \\
\hline 7 & 40.5 & 8.11 & 36.4 & 48.5 & 15.2 & 43.8 & 46.9 & 6.25 & 72.4 & 24.1 & 3.45 & 35.3 & 44.1 & 20.6 \\
\hline
\end{tabular}

Notes: This information is derived from the 2004 survey of workers, in which 289 workers were surveyed. The friendship number reports whether the individual was listed as the first friend, the second friend, and so forth. The table reports for each friendship number, whether that friendship is an old or reciprocal friendship, and for each friendship number and activity type, the percentage of respondents that reported any given frequency of interaction. 
Table A3: Work Related Attitudes

\begin{tabular}{|c|c|c|c|c|c|}
\hline & Agree Strongly & Agree & Indifferent & Disagree & Disagree Strongly \\
\hline I would pick faster if I could win a prize & 29.2 & 28.5 & 22.6 & 10.8 & 9.03 \\
\hline I would pick faster if I could be promoted to supervisor & 27.9 & 28.3 & 24.4 & 12.7 & 6.71 \\
\hline I would pick faster if I worked next to the fastest pickers & 29.4 & 30.4 & 19.9 & 12.2 & 8.04 \\
\hline \multirow[t]{2}{*}{ I would pick faster if I worked next to my friends } & 24.6 & 26.7 & 27.7 & 14.4 & 6.67 \\
\hline & $\begin{array}{c}\text { Fixed } \\
\text { Hourly Wage }\end{array}$ & $\begin{array}{l}\text { Individual } \\
\text { Piece Rate }\end{array}$ & $\begin{array}{c}\text { Group } \\
\text { Piece Rate }\end{array}$ & & \\
\hline \multirow[t]{2}{*}{ How would you like to be paid for your work on this farm? } & 74.0 & 23.3 & 2.74 & & \\
\hline & $\begin{array}{l}\text { My Best } \\
\text { Friends }\end{array}$ & $\begin{array}{l}\text { The Fastest } \\
\text { Pickers }\end{array}$ & $\begin{array}{l}\text { It Does Not } \\
\text { Matter }\end{array}$ & & \\
\hline $\begin{array}{l}\text { If you had to work in a group and you were paid a group } \\
\text { piece rate, who would you want to be in your group? }\end{array}$ & 52.7 & 33.6 & 13.7 & & \\
\hline
\end{tabular}

Notes: The information is derived from the 2003 worker questionnaire in which 300 workers were surveyed. The Tables report the proportion of workers that provide each response. 
Figure 1: Number of Times Mentioned as a Friend by a Co-worker

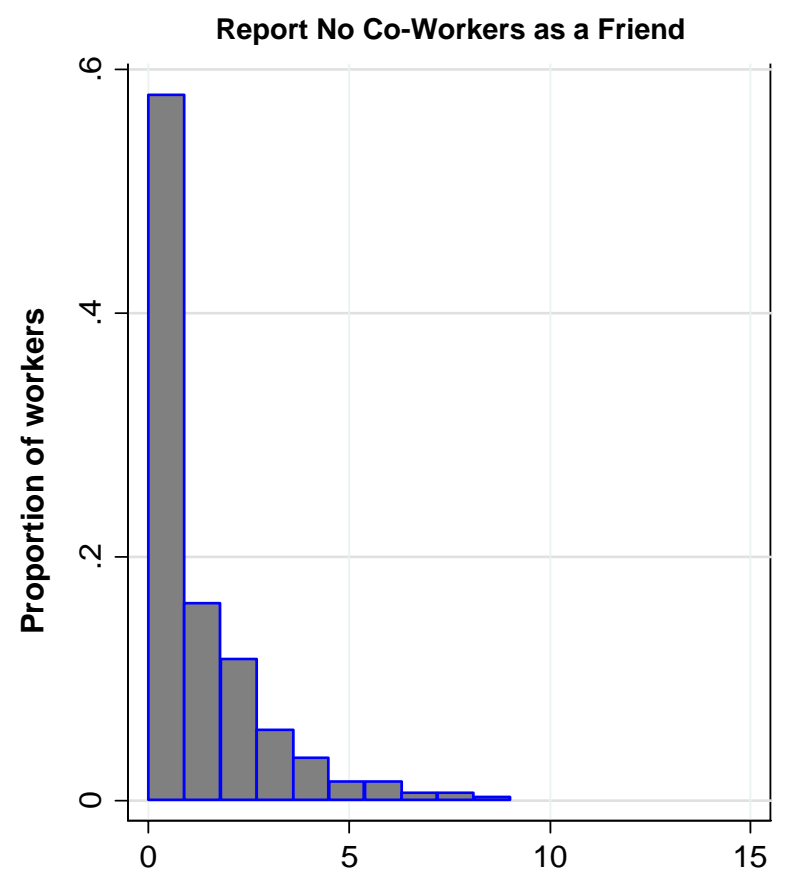

Report At Least One Co-Worker as a Friend

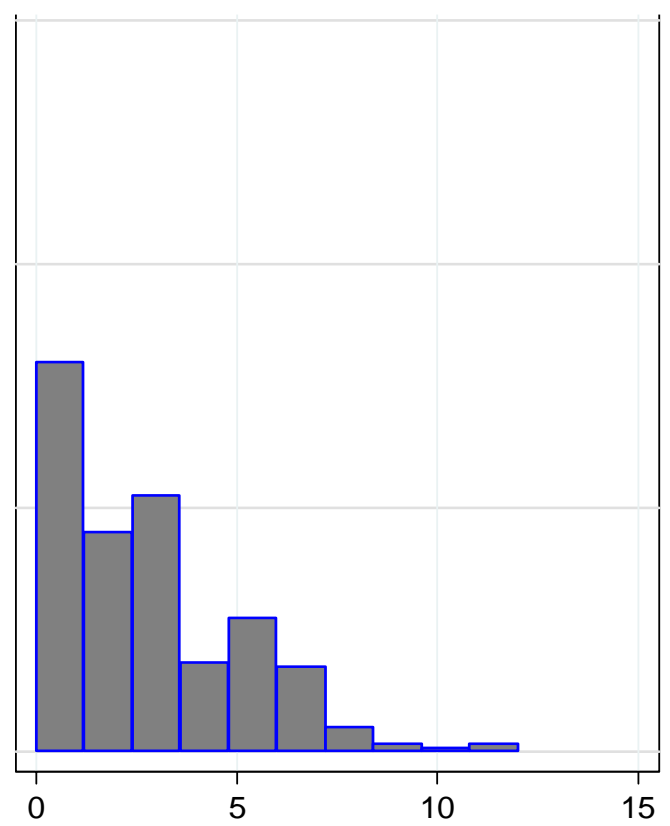

Number of times worker is mentioned by a co-worker as a friend of theirs
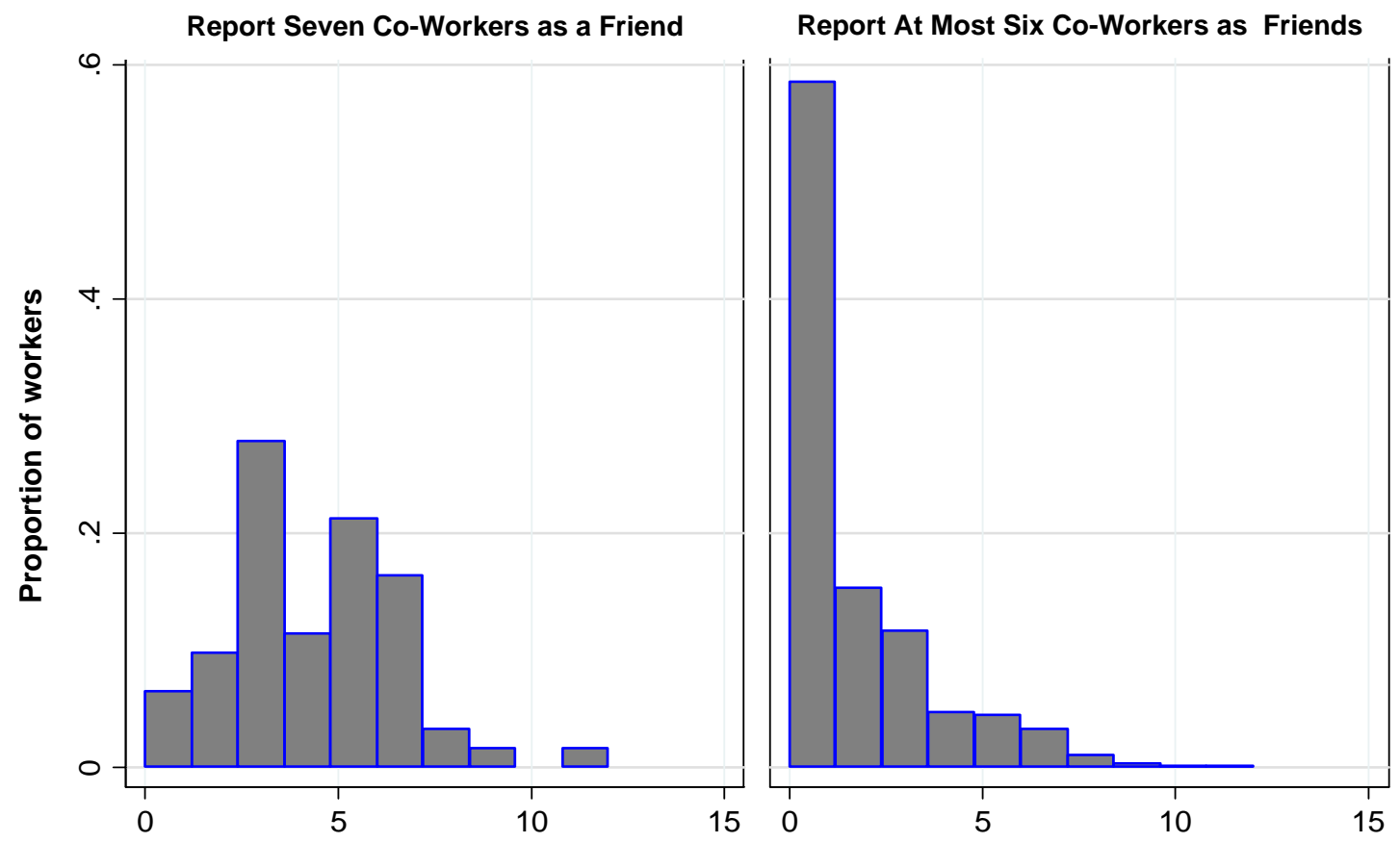

Number of times worker is mentioned by a co-worker as a friend of theirs

Notes: This information is obtained from the 2003 worker questionnaire in which 300 workers were surveyed. Each worker was asked to list up to seven of their friends in the workplace. 

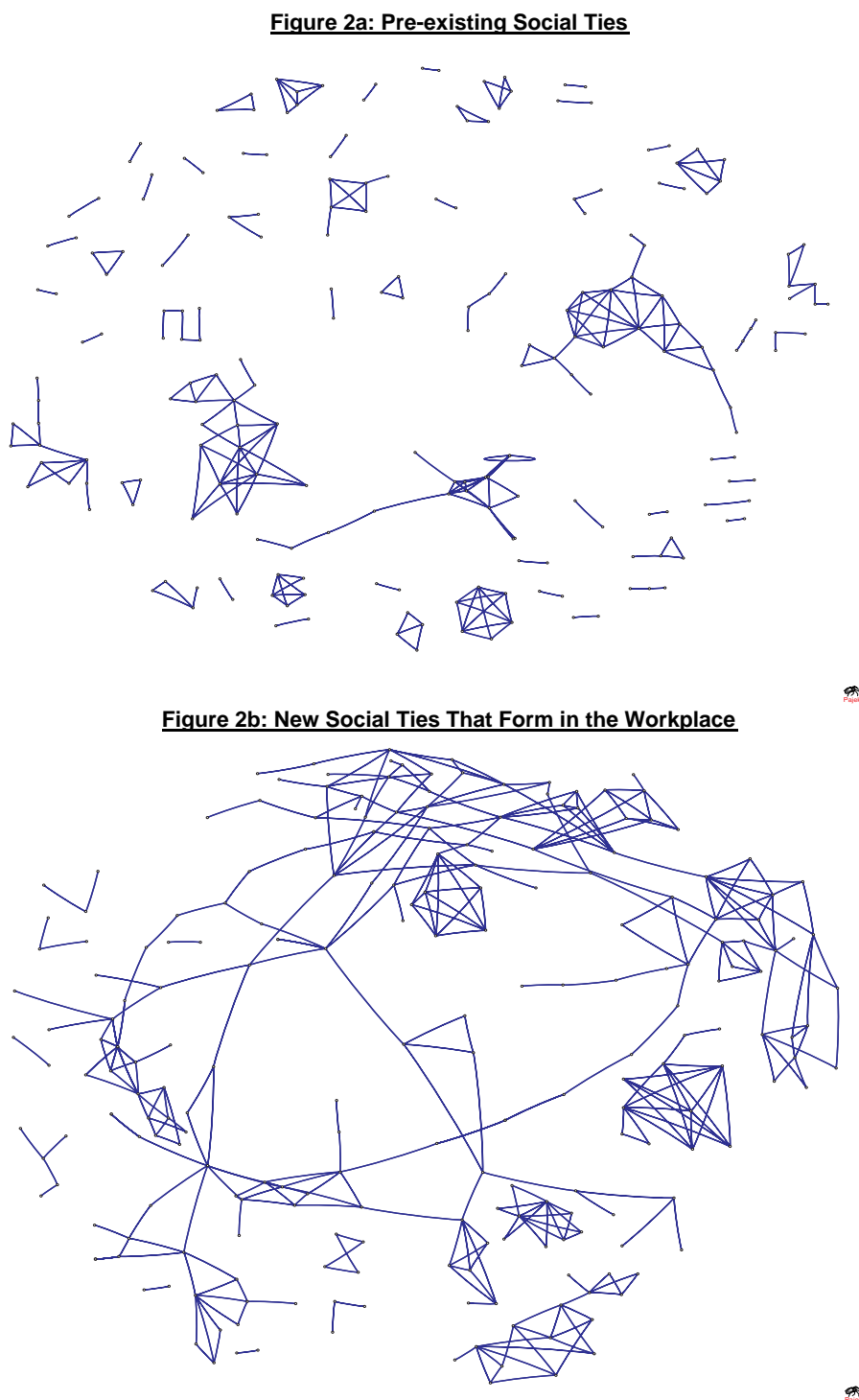

Figure 2c: The Social Network of Friendships in the Workplace

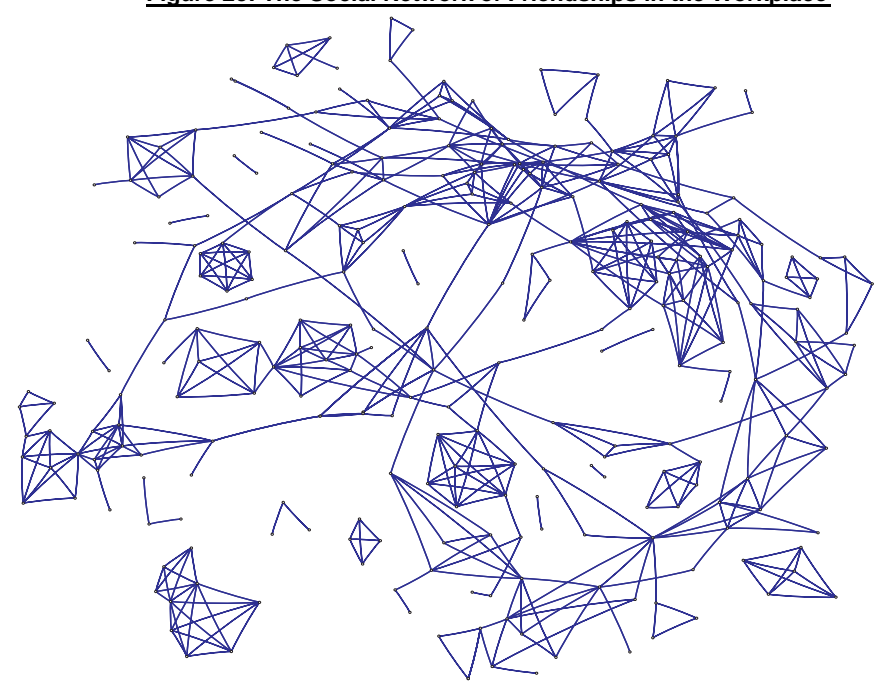

Notes: All figures are constructed using the Payek software. Each node represents a single worker. A link exists between any pair of workers if either workeri reports 